\title{
Figures, Tables and Maps
}

\section{Figures}

Figure 3.1 Welsh Romani vowels (based on Sampson 1926b)

66

\section{Tables}

Table 2.1 Romani innovative past-tense person markers and their MIA pronominal predecessors

Table 2.2 Romani archaic present-tense subject concord markers and their OIA predecessors

Table 3.1 Welsh Romani consonant system (based on Sampson 1926b)

Table 3.2 Welsh Romani major nominal inflection classes (based on Sampson 1926b)

Table 3.3 Layer II case markers in European Romani and Welsh Romani

Table 3.4 Inherited Romani adjective inflection paradigm: baro 'big'

Table 3.5 Attested person conjugation forms for English Romani

Table 3.6 Word-initial segments in British Romani and other Romani dialects

Table 3.7 Initial palatalisation of inherited segments in Angloromani and other Romani dialects

Table 3.8 Selected lexical items in Angloromani and other Romani dialects

Table 4.1 Variation in the shape of selected word forms

Table 4.2 Recreating minimal pairs in Angloromani (based on Matras et al. 2007: 164-5)

Table 4.3 Word formation with - $(\mathrm{m})$ engra found in the corpus 105

Table 4.4 Formations in -ipen/-iben from the corpus 107

Table 4.5 Compounds in divvus 
Table 4.6 Compounds in mush 108

Table 4.7 Location deixis for four speakers 112

Table 4.8 Angloromani numerals documented in the corpus 117

Table 4.9 Corpus frequency of expressions, predecessors and meanings (top twenty) 127

Table 4.10 Speakers' knowledge of expressions (variable word form) 128

Table 4.11 Retrieval patterns: most frequent immediate retrievals and volunteered expressions

\section{Maps}

Map 2.1 Some major isogloss clusters in Romani

Map 2.2 Conventional dialect classification grid in Romani linguistics 